\title{
Urban Seismic Hazard Mapping for Memphis, Shelby County, Tennessee
}

\section{Earthquakes cannot be predicted but scientists can forecast how} strongly the ground is likely to shake as a result of an earthquake. Seismic hazard maps provide one way of conveying such forecasts. The U.S. Geological Survey (USGS), which produces seismic hazard maps for the Nation, is now engaged in developing more detailed maps for vulnerable urban areas. The first set of these maps is now available for Memphis, Tenn. (fig. 1).

\section{Who Uses Urban Seismic Hazard Maps?}

A number of public and private groups use hazard maps to minimize losses resulting from earthquake shaking. The maps are used to guide city planners and engineers in designing safe structures and determining where they should be located. Emergency responders use hazard maps in planning post-earthquake relief efforts. Insurance companies use hazard maps to examine the risk to their portfolios in order to ensure financial recovery after damaging earthquakes.

\section{What is Seismic Hazard?}

Seismic hazard refers to a measure of the shaking, or ground motion, from earthquakes that can damage our man-made environment. The hazard depends on the magnitudes and locations of likely earthquakes, how often they occur, and the properties of the rocks and sediments that earthquake waves travel through.

In the central U.S., earthquakes occur along the New Madrid seismic zone; active faults in this region are buried by the thick sedimentary deposits of the Mississippi embayment (fig. 2).

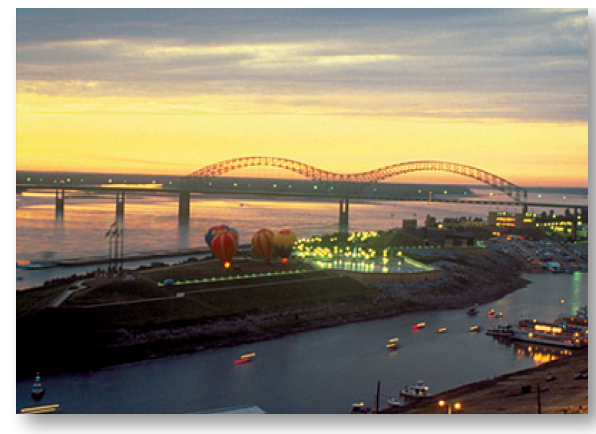

Figure 1. Photograph of part of the mapped area: the view from downtown Memphis, Tenn., of Mud Island between the Wolf and Mississippi Rivers, and the I-40 bridge crossing from downtown to West Memphis, Ark.

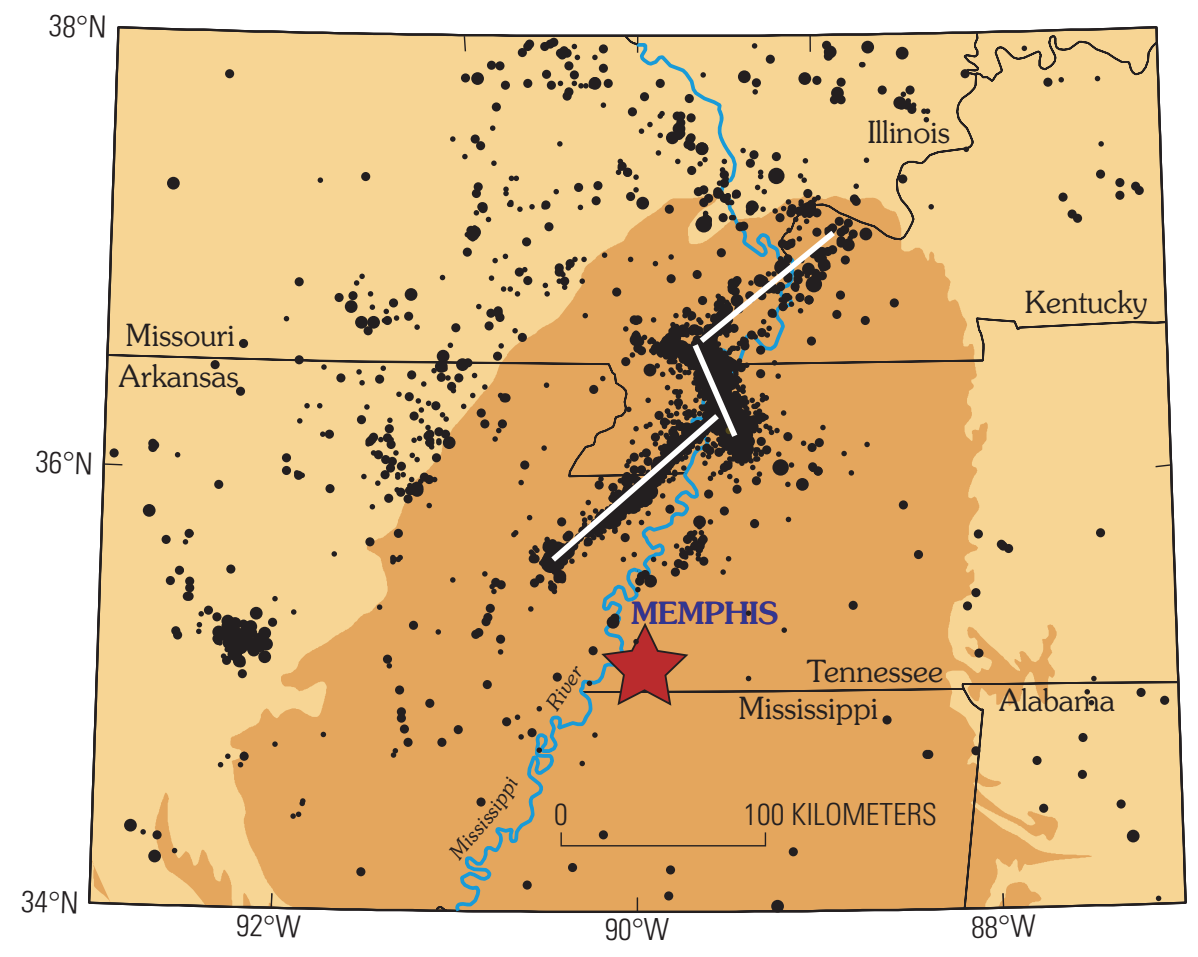

Figure 2. Map of the region surrounding Memphis, Tenn. The darker orange area is covered by thick sediments, called the Mississippi embayment. These sediments significantly affect how the ground shakes during earthquakes. White lines indicate likely locations of major faults (buried beneath the sediments), and black dots show the locations of earthquakes recorded since the mid-1970s. Blue line is Mississippi River. 

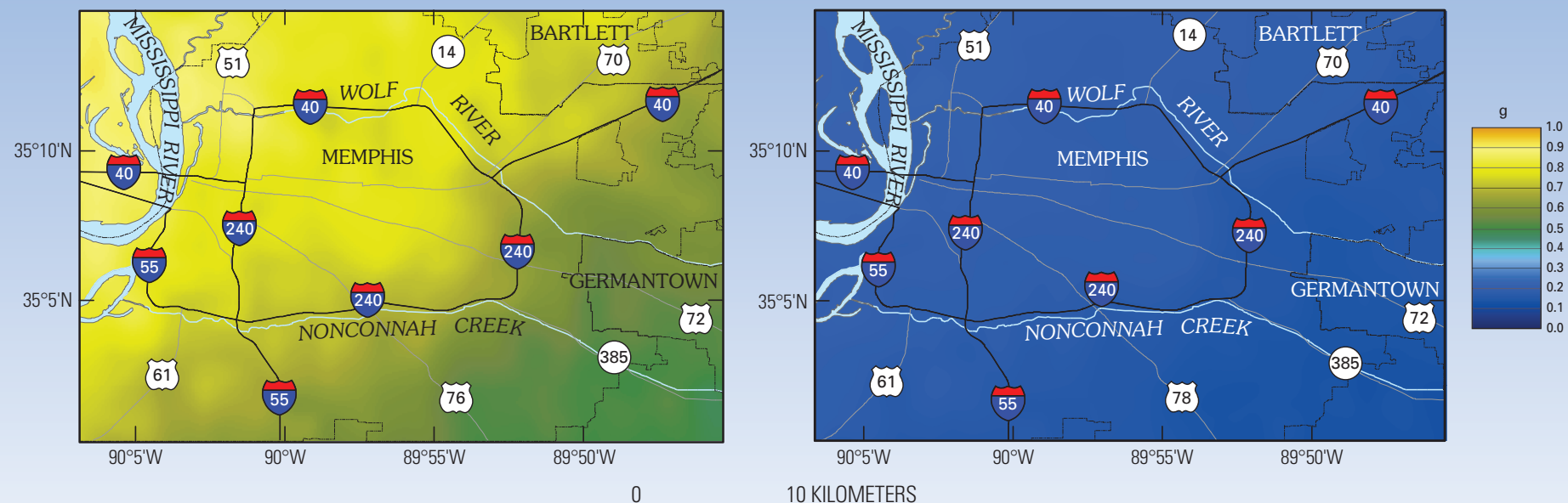

Figure 3. Two of the probabilistic urban seismic hazard maps for the Memphis, Shelby County, Tenn., area. These maps show accelerations with oscillation periods of 1.0 second, with a 2 percent (LEFT) and 10 percent (RIGHT) chance of being exceeded in 50 years. The color scale shows the acceleration level, measured in gravity, " $g$ " units; $1 \mathrm{~g}$ is the acceleration of a freely falling object due to gravity.

Seismic hazard maps may also be either probabilistic or deterministic. In an earthquake-prone area, an engineer might assume a particular earthquake will occur and needs to know how hard it is likely to shake the ground. These needs call for "deterministic," or "scenario," forecast maps. Such maps might be used when conservative estimates and worstcase scenarios are called for, such as when building critical facilities. Deterministic maps do not take into account the likelihood of such a scenario occurring.

When considerations of likelihood become important, a "probabilistic" forecast map may be more appropriate.
Probabilistic seismic hazard maps attempt to account for all earthquakes that might affect an area. They incorporate information about seismic activity and the locations of active faults, as well as estimates of the time interval between earthquake recurrences.
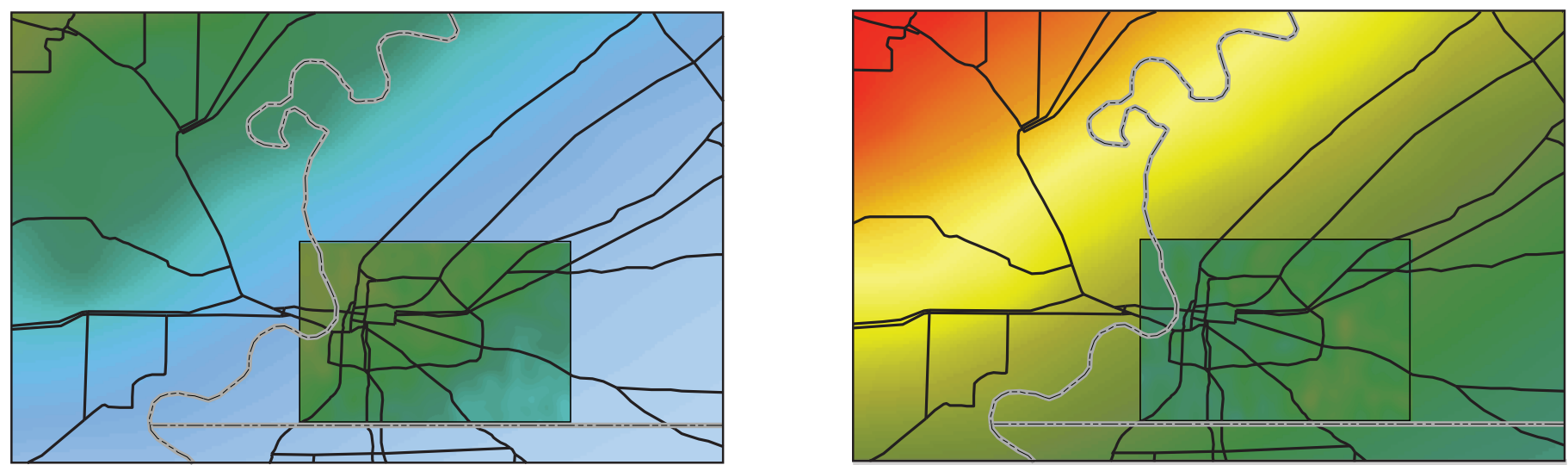

Figure 4. The Memphis maps show a reduction in short-period ( 0.2 second) shaking by as much as 30 percent (TOP RIGHT INSET MAP) and an increase in longer period shaking, nearly doubling the motions in the 1.0 -secondperiod map (TOP LEFT INSET MAP), compared to the National Seismic Hazard map (BOTTOM MAP and TOP BACKGROUND MAPS). These differences result directly from including the effects of the sediments, which are not accounted for in the National Seismic Hazard maps. The color scale shows the acceleration level, measured in percent of gravity or " $g$ " units; 100 percent $\mathrm{g}$ is the acceleration of a freely falling object due to gravity.

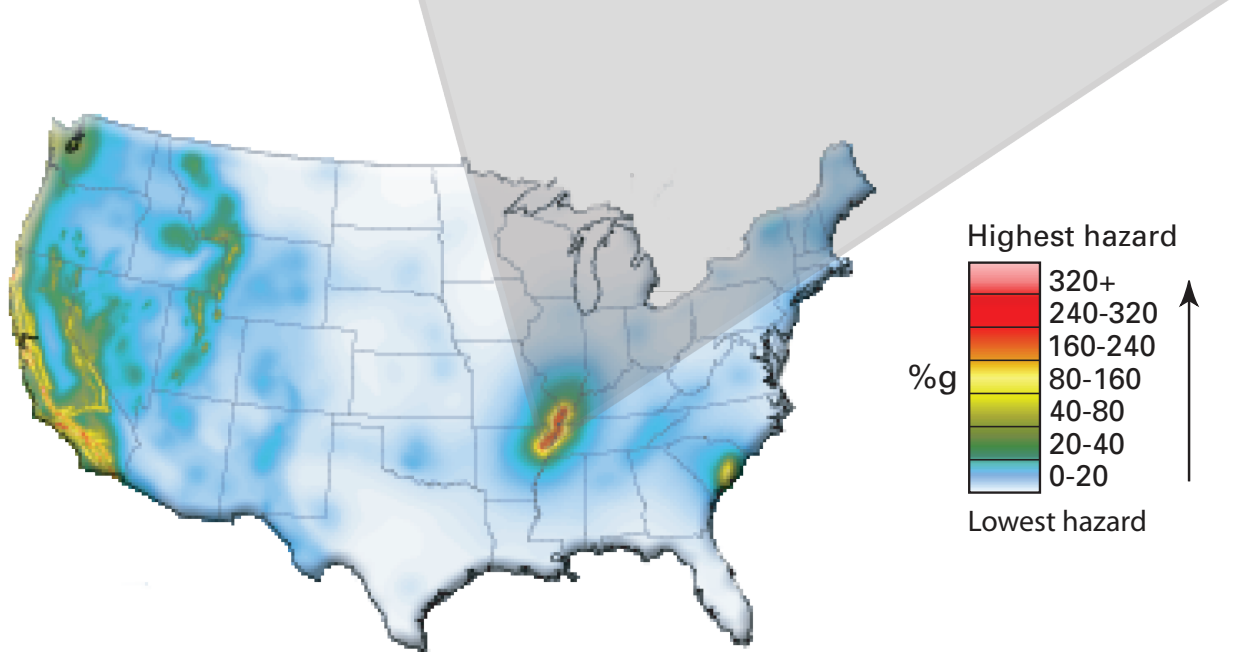




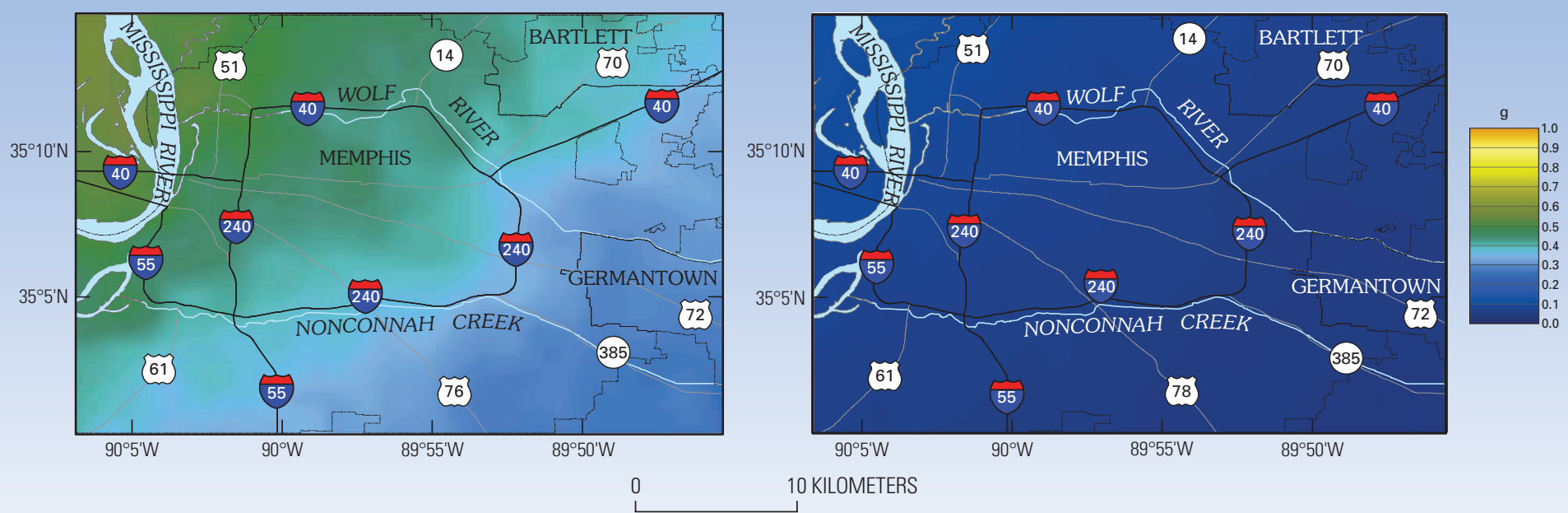

Figure 5. Scenario maps for the Memphis, Shelby County, Tenn., area. The map on the LEFT is for a magnitude 7.7 earthquake, a possible repeat of the December 16, 1811, earthquake, and the map on the RIGHT is for a magnitude 6.2 earthquake, like the Marked Tree, Ark., event in 1843. The ground motions shown correspond to shaking with an oscillation period of 1.0 second.

The USGS has developed a series of probabilistic seismic hazard maps for the Nation. These maps consider a time period of 50 years, a typical building lifetime. At all locations the maps answer the question, "At some specific probability, what level of shaking is likely to be exceeded?" (that is, the probability of exceedence). For example, the maps of the Memphis area (fig. 3) show the ground motions that have a 2 percent (left) and a 10 percent (right) chance of being exceeded within the next 50 years. The predicted motions shown on the 2 percent maps are larger because they allow for the more infrequent, large earthquakes.

\section{The Memphis Maps}

Although the USGS National Seismic Hazard maps cover the entire Nation, they are not sufficiently detailed to include near-surface geologic conditions, which can greatly affect ground shaking. Therefore, the USGS is also developing complementary urban hazard maps for earthquake-prone metropolitan areas. These urban hazard maps are much better predictors of local variations in ground shaking because they take into consideration the near-surface geology. The first set of these urban maps is now available for Memphis, Tenn.

Memphis is a densely populated urban area, built on a very thick layer (nearly 1 $\mathrm{km}$ ) of sediments that extends over much of the broad Mississippi Valley. Near-surface sediments are variable from place to place beneath the city, but in general the sediment layer thickens toward the northwest.
A comparison of the Memphis and the National Seismic Hazard maps (fig. 4) highlights the importance of including the influence of shallow geologic structure when estimating ground motion. The national maps show an increase in hazard toward the northwest because the faults of the New Madrid seismic zone lie northwest of Memphis. As a result of the enhanced dissipation of waves traveling through thick sediments, the Memphis maps show reductions in short-period shaking (right map, fig. 4), implying that single family homes and other small buildings are not as vulnerable as previously thought. However, the thick sediments also resonate at some frequencies and cause increases in longer period shaking (left map, fig. 4); this implies a

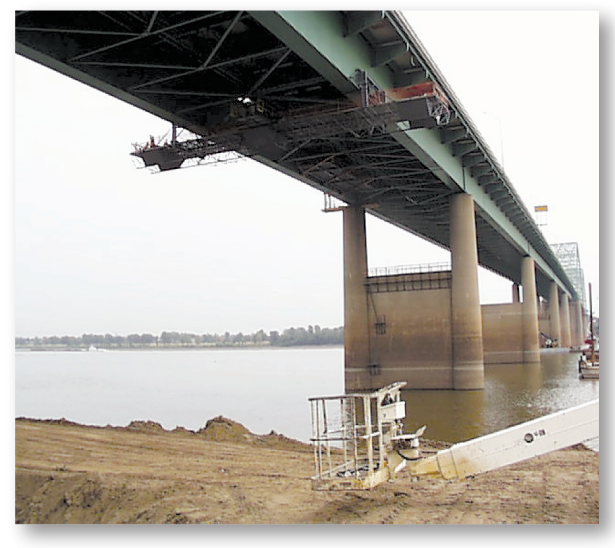

Figure 6. Effective strengthening of existing structures, like the recent retrofitting of the I-40 bridge crossing the Mississippi River, requires accurate information about likely earthquake ground shaking. (Photo by G. Patterson, CERI, University of Memphis.) greater vulnerability of tall buildings or long bridges to earthquake shaking. The average motions for both maps (about $0.7 \mathrm{~g}$ each; $1.0 \mathrm{~g}$ is the acceleration of a falling object due to gravity) are large enough to cause significant damage.

The Memphis seismic hazard maps show estimated values of ground acceleration (an indicator of the force of the seismic waves). These maps display ground acceleration in two ways: (1) peak ground acceleration (PGA), the largest value of the total motion, consisting of many types of seismic waves, and (2) spectral accelerations ( $\mathrm{Sa}$ ), consisting of waves with periods of either 0.2 or 1.0 second. Peak ground accelerations of as little as $0.1 \mathrm{~g}$ may be strongly felt and do light damage, and severe shaking and moderate to heavy damage may occur for values above about $0.3 \mathrm{~g}$.

The USGS Memphis urban seismic hazard maps include probabilistic maps (fig. 3) showing ground motions expected to be exceeded during the next 50 years with probabilities of 2,5 , and 10 percent (5 percent maps are not shown here but are available online at http://earthquake.usgs. gov/regional/ceus/urban_map/memphis/ index.php). Products also include scenario maps for magnitude 7.7 (left, fig. 5) and magnitude 6.2 (right, fig. 5) earthquakes. The magnitude 6.2 scenario map shows ground motions expected for a repeat of an earthquake that occurred near Marked Tree, Ark., in 1843. The magnitude 7.7 scenario map was chosen to show the expected effect of a repeat of an earthquake that occurred on December 16, 1811. This 
earthquake occurred along the southern fault shown on the map in figure 2. Urban seismic hazard maps like these provide needed information for the design of new structures and retrofitting (fig. 6) of existing ones.

\section{Related Products}

The investigations done to produce the Memphis hazard maps resulted in a variety of other products. Among these are maps of the surficial geologic materials (fig. 7) and maps showing the likelihood of liquefaction (not shown). Liquefaction occurs when water-saturated sediments lose their cohesive strength during violent ground shaking.

An online database of sediment properties determined from well and boring logs can be found at http://gwidc. memphis.edu/website/introduction/. Also, a variety of technical and nontechnical reports are available at http://earthquake. usgs.gov/regional/ceus/urban_map/memphis/index.php.

\section{Making Urban Seismic Hazard Maps}
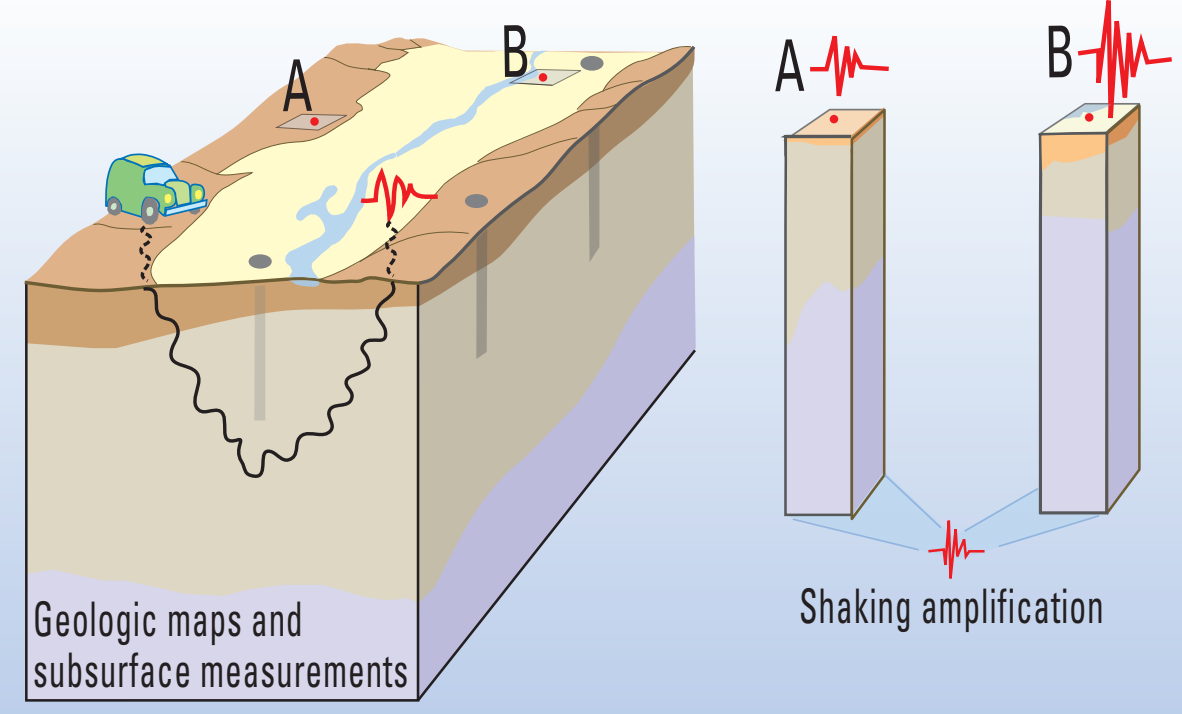

Figure 8. Geologists map the soils and sediments at the surface. Properties of these surficial materials, how deeply they extend, and properties of the materials below are characterized from measurements made in boreholes drilled for construction projects and in water wells. Much like X-rays or ultrasound imaging, information about the subsurface also comes from subsurface imaging techniques. These data are then integrated to construct a 3-D model of the layering of soils and sediments.
The soil and sediment layers change the seismic waves that travel upward through them, from an earthquake below. The 3-D model describes the layering beneath any particular location, and is used to calculate how the shaking from the waves will vary from place to place. For example, the sediments in the river flood plain beneath site B may amplify some types of shaking more than at site $A$ located on the bluffs.

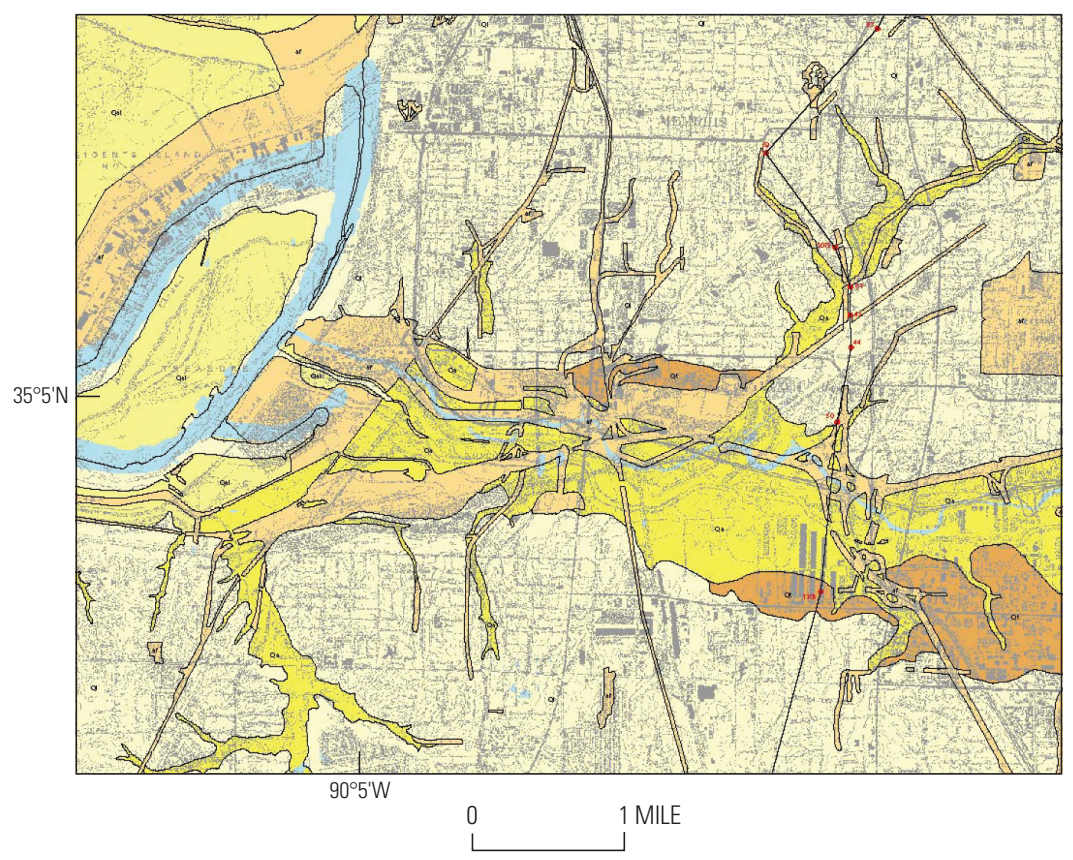

Figure 7. Geologic map of the southeastern portion of the Memphis mapping area (by D. Moore and S. Diehl). Colors show different sediment types; most of this area (beige color) is covered by sediments (called loess) carried by wind and deposited during the last glacial period, and by river flood-plain sediments (yellows and tans). This and other new geologic maps for Memphis are available online at http://earthquake.usgs.gov/regional/ceus/urban_map/memphis/index.php.

\section{For More Information Contact:}

Joan Gomberg or Eugene Schweig Earthquake Hazards Program

U.S. Geological Survey

3876 Central Avenue, Suite 2

Memphis, TN 38152

901-678-4974

gomberg@usgs.gov or

schweig@usgs.gov

Central U.S. Hazard Maps are at: http://earthquake.usgs.gov/regional/ ceus/urban_map/index.php/

Earthquake Hazards Program: http://earthquake.usgs.gov/

Partners: Regional Seismic Networks, Central U.S. Earthquake Consortium (CUSEC), Mid-America Earthquake Center, and university collaborators

\section{Written by Joan Gomberg}

Graphics and layout design by Lisa Wald and Richard Dart

This Fact Sheet is available online at: http://pubs.usgs.gov/fs/2005/3142/ 